\title{
Editorial: In Memoriam: Anastasios (Tas) N. Venetsanopoulos
}

\author{
Dimitri Androutsos $^{1}$ - Kostas Plataniotis ${ }^{2}$ - A. Enis Cetin ${ }^{3}$
}

Received: 17 October 2015 / Accepted: 19 October 2015 / Published online: 4 November 2015

(C) Springer-Verlag London 2015

On November 17, 2014, the signal processing world lost Anastasios N. Venetsanopoulos. Tas, as he was known to his friends and colleagues, had a long and prolific career that spanned over 40 years, wherein he established himself as an internationally renowned and respected researcher, a prolific author and an exceptionally gifted educator. Tas was widely regarded as a world authority and a pioneer of the signal processing field. Specifically, his research in multimedia systems, digital signal and image processing, digital communications, biometrics and neural networks is internationally acclaimed, both in academia and industry, and resulted in nine books (including [1-4]), 35 book chapters and 900 technical papers with over 14,000 citations. He was a mentor to over 160 graduate students and researchers and an educator to thousands of undergraduate students while serving, with distinction, in a number of key administrative positions within the University of Toronto and Ryerson University, both in Toronto, Canada.

Tas earned his Bachelor of Electrical and Mechanical Engineering degree from the National Technical University of Athens in 1965, and a Master of Applied Science, a Master of Philosophy and a Doctor of Philosophy in Electrical Engineering from Yale University in 1966, 1968 and 1969, respectively. He joined the Department of Electrical Engi-

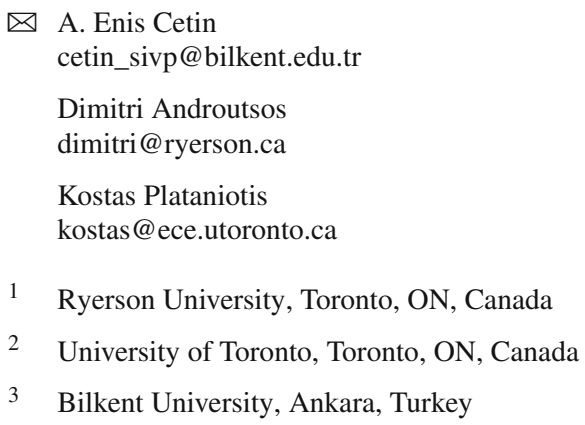

neering at the University of Toronto in September 1968, and he led its Faculty of Applied Science and Engineering, as its 12th Dean (2002-2006). In late 2006, he joined Ryerson University as its first Vice-President of Research and Innovation until 2010 and continued to do research, supervise and mentor graduate students and teach.

Professor Venetsanopoulos exemplified the standard of academic excellence. He was an outstanding scholar who made exceptionally important and fundamental contributions to the fields of telecommunications, signal and image processing, multimedia and biometrics research that have been applied globally and throughout many related areas. While his research productivity was outstanding, it is the depth and quality of his work that has led to his unparalleled international reputation and his ability to move science from laboratory research into the real world by identifying and recognizing how the applications of his research could fit to real-life situations with very positive social and economic outcomes. Tas made significant advances to our understanding of multidimensional filter theory and design, and opened up new vistas in telecommunications, nonlinear filter design, higher-order statistical signal processing [5], multimedia [6], neural networks and biometrics. He established the first and most successful method for the design of conventional multidimensional digital filters and his framework remains as valid as ever in modern-day filter design.

In the area of Digital Image Processing, Tas was regarded as one of the leading international authorities. He contributed significant theoretical results to the area of color image processing and analysis, introducing a number of techniques for color image enhancement, filtering and analysis.

In his long and distinguished career, he also had exemplary professional service and received many accolades and awards. He served as Chair on numerous boards, councils and technical conference committees of the IEEE. He served 
as Chair of the IEEE Toronto Section from 1977 to 1979 and the IEEE Central Canada Council from 1980 to 1982 . He was President of the Canadian Society for Electrical Engineering and Vice President of the Engineering Institute of Canada from 1983 to 1986 . He was a Guest Editor and Associate Editor for several IEEE journals and the Editor of the Canadian Electrical Engineering Journal (1981-1983). He was also the General Chair of the IEEE International Conference of Acoustics, Speech and Signal Processing (ICASSP 1991). He was a member of the IEEE Signal Processing, Communications, Circuits and Systems and Computer Societies of the IEEE. In 1994, Tas received an Honorary Doctorate from the National University of Technology in Athens, Greece. He was also awarded the "Excellence in Innovation" Award from the Information Technology Research Centre of Ontario (1996), the "Third Millennium Medal of the IEEE" (2000) and the "IEEE McNaughton Medal" (2003). He was a Fellow of the IEEE, a Fellow of the Engineering Institute of Canada, a Fellow of the Canadian Academy of Engineering and a Fellow of the Royal Society of Canada.

In this special issue, we have six papers which are authored by former students and colleagues of Tas [7-12].

\section{References}

1. Pitas, I., Venetsanopoulos, A.N.: Nonlinear Digital Filters: Principles and Applications. Springer, Berlin (1990)

2. Karayiannis, N., Venetsanopoulos, A.N.: Artificial Neural Networks Learning Algorithms, Performance Evaluation, and Applications. Springer, Berlin (1993)
3. Plataniotis, K.N., Venetsanopoulos, A.N.: Color Image Processing and Applications. Springer, Berlin (2000)

4. Lu, H., Plataniotis, K.N., Venetsanopoulos, A.N.: Multilinear Subspace Learning: Dimensionality Reduction of Multidimensional Data. Chapman and Hall/CRC, London (2013)

5. Alshebeili, S.A., Venetsanopoulos, A.N., Enis Cetin, A.: Cumulant based identification approaches for nonminimum phase FIR systems. IEEE Trans. Signal Process. 41(4), 1576-1588 (1993)

6. Androutsos, P., Androutsos, D., Venetsanopoulos, A.N.: Small world distributed access to multimedia data. IEEE Signal Process. Mag. 23(2), 142-153 (2006)

7. Vretos, N., Tefas, A., Pitas, I.: A novel dimensionality reduction technique based on Kernel optimization through graph embedding. SIViP. (2015). doi:10.1007/s11760-015-0832-y

8. Reiche, B., Moody, A., Khademi, A.: Effect of image standardization on FLAIR MRI for brain extraction. SIViP. (2015). doi:10. 1007/s11760-015-0831-z

9. Rzeszutek, R., Androutsos, D.: Propagating sparse labels through edge-aware filters. SIViP. (2015). doi:10.1007/s11760015-0833-x

10. Hadi, M.A., Alshebeili, S., Jamil, K., El-Samie, F.A.: Compressive sensing applied to radar systems - an overview. SIViP. (2015). doi:10.1007/s11760-015-0824-y

11. Tofighi, M., Kose, K., Enis Cetin, A.: Denoising images corrupted by impulsive noise using projections onto the epigraph set of total variation function (PES-TV). SIViP. (2015). doi:10.1007/s11760015-0827-8

12. Smolka, B., Kusnik, D.: Robust local similarity filter for the reduction of mixed Gaussian and impulsive noise in color digital images. SIViP. (2015). doi:10.1007/s11760-015-0830-0 